\title{
Preceito constitucional do caráter nacional dos partidos políticos e a verticalização das coligações ${ }^{1}$
}

\author{
Marilene de Carvalho \\ Profa. Ana Cláudia Duarte Pinheiro ${ }^{3}$
}

\begin{abstract}
Resumo
Cuida-se de analisar a vinculação das coligações partidárias nas eleições estaduais e municipais às diretrizes das coligações realizadas na eleição nacional para Presidente da República, a chamada "verticalização" das coligações eleitorais; e sua relação com o preceito constitucional do caráter nacional dos partidos políticos. A questão tornou-se controvertida com a expedição da Resolução $n^{\circ}$. 20.993/2002 do TSE, afirmando a regra da verticalização das coligações partidárias para fins eleitorais. Para evitar novas interpretações, o Congresso Nacional, por meio da EC $n^{\circ}$. 52/2006, modificou o art. 17, parágrafo 10 da CF, e afastou aquela interpretação do TSE. O STF não se manifestou sobre o mérito da controvérsia sobre a possibilidade da verticalização frente aos preceitos constitucionais que balizam os partidos políticos; como o preceito do caráter nacional instituído no art. 17; inciso I da CF. Busca-se, neste estudo, mostrar que o caráter nacional dos partidos, no âmbito da formação de alianças eleitorais; pressupõe que estes tenham unidade em suas ideologias, para não transformar as coligações em meros instrumentos convenientes ao alcance do poder. E nesse sentido, vislumbra-se que a EC no. $52 / 2006$ veio de encontro às conclusões de debates e estudos feitos em torno do Projeto de Lei no. 2.679/03; o qual pretende restringir o uso de coligações apenas às eleições para Presidente da República; como medida de contenção da fragmentação partidária no país e da falta de ideologias nítidas em nossos partidos políticos.
\end{abstract}

Palavras-Chave: Partidos políticos; Caráter nacional; Coligações eleitorais; Verticalização.

\section{Introdução}

Os partidos políticos brasileiros são formados em caráter nacional, por disposição constitucional, com "filosofias que respeitam a toda a coletividade nacional, e não apenas uma circunscrição estadual ou municipal", como argúi o Ministro do STF, Aires Brito, em seu voto na ADI n. 0 3.685-8. O preceito vem exposto no artigo 17, inciso I, da Constituição Federal.

1 O presente artigo originou-se do Trabalho de Conclusão de Curso realizado sob a Orientação da Professora Ana Cláudia Duarte Pinheiro.

2 Acadêmica do 50 ano do curso de Direito da UEL.

3 Professora do Curso de Direito da UEL e Mestre em Direito Negocial pela UEL. 
A interpretação desse preceito constitucional foi objeto de várias discussões, iniciadas devido à expedição da Resolução $n^{\circ}$. 20.993/02 do Tribunal Superior Eleitoral, norma interpretativa, que relacionou o caráter nacional dos partidos políticos com a "verticalização" das coligações nas eleições proporcionais de 2002.

Chama-se de "verticalização" a vinculação das coligações partidárias nas eleições nos Estados e nos Municípios, àquela coligação feita pelo partido em nível nacional para as eleições presidenciais.

Antes mesmo dessas discussões, o problema do caráter nacional dos partidos já se mostrava abertamente no cenário político brasileiro, tendo em vista a diversidade nas alianças eleitorais feitas entre partidos em cada circunscrição eleitoral no país.

\section{Caráter nacional versus autonomia}

Ao estabelecer o caráter nacional dos partidos políticos, a CF/88 determinou que eles fossem criados com abrangência em todo o território nacional, impedindo assim, a formação de partidos estaduais, distritais ou municipais.

Considera-se que o partido político tem caráter nacional, após adquirir personalidade jurídica com seu registro no Cartório do Registro de Pessoas Jurídicas da Capital Federal, quando demonstra um apoiamento de eleitores, correspondente a pelo menos, meio por cento dos votos válidos dados na última eleição geral para a Câmara dos Deputados, distribuídos por um terço ou mais dos Estados, com um mínimo de um décimo por cento do eleitorado que haja votado em cada um deles; conforme dispõe o artigo 7ํㅡ, parágrafo 1으, da Lei 9.096/95. Para o cômputo desse número, a lei partidária sempre considera o Distrito Federal em equiparação aos Estados.

O apoiamento dos eleitores é promovido pelo Partido após adquirir personalidade jurídica. Os eleitores que apoiarem o novo partido comparecem nas Zonas Eleitorais com seu título de eleitor; e assinam listas dispostas especificamente para este fim. Após, a pedido do Partido, o escrivão expede certidão que comprove o apoiamento dos eleitores. Estas certidões são levadas junto a outros documentos para o registro do partido no TSE.

A caracterização dos partidos como entidades em nível nacional, pressupõe o apoio de eleitores em pelo menos nove Estados brasileiros. Para isso, é necessário que o partido esteja presente em todos eles com seu conteúdo principal: suas ideologias e suas ações. 
Faz-se mister, então, que exista um centro de direção nacional do partido, de onde surjam as diretrizes principais do partido, do qual se estabeleçam as linhas gerais e harmônicas, sobre o cumprimento de seu programa, de sua ideologia, e de suas ações. Essas diretrizes devem ser tomadas para valerem em toda a extensão territorial do país, onde haja órgão de determinado partido, e não apenas nos Estados onde se pretende conseguir o apoiamento de eleitores. Assim, tais decisões, de ordem ideológica, devem ser válidas para todos os seus diretórios estaduais.

De forma contrária, realizando decisões diversas para cada Estado, ou Município, seu caráter nacional estaria sendo burlado pela adoção de ideologias diversas e até contraditórias no interior do partido, conforme os interesses regionais dos partidos, por ora, ligados apenas à conquista do poder, e em prejuízo a um interesse que deveria ser de cunho nacional.

A autonomia dos partidos refere-se à forma como eles existem: sem sofrerem interferência de qualquer órgão governamental ou entidade privada, principalmente, de estrangeiros; os partidos definem o conteúdo de seus programas, seus objetivos políticos, e em seus estatutos, estabelecem a estrutura interna, a organização e seu funcionamento. Trata-se de liberdade dada aos partidos para as decisões internas da agremiação, em suas relações particulares, considerando apenas a natureza privada das instituições.

O texto do artigo 17, parágrafo 1으, anterior à Emenda Constitucional 52/06, tratava a autonomia dos partidos políticos conforme explicado anteriormente, na seguinte redação:

\footnotetext{
Art. 17. [...]

$[\ldots]$

$\S 1$ É assegurada aos partidos políticos autonomia para definir sua estrutura interna, organização e funcionamento, devendo seus estatutos estabelecer normas de fidelidade e disciplinas partidárias (Constituição da República Federativa do Brasil; 1988).
}

Tais preceitos foram repetidos na Lei $n^{\circ}$. 9.096/95, que dispõe sobre os Partidos Políticos, e na Lei $n^{\circ}$. 9.504/97, que trata das Eleições. Os artigos 3 e 5o da Lei $n^{\circ}$. 9.096/95 diferenciam bem o significado do caráter nacional dos partidos políticos, que diz respeito ao âmbito de sua atuação; e da autonomia dos mesmos, que versa sobre sua estrutura interna, organização e funcionamento. O artigo 60 da Lei 9.504/97, disciplina a forma como os 
partidos podem realizar alianças nas eleições, impondo limites que visam preservar, na prática, o caráter nacional dos partidos.

Assim, percebe-se que a Constituição Federal e a legislação infraconstitucional privilegiam a formação de um sistema partidário no qual haja uma unidade nacional nos partidos, com ideologias e programas estabelecidos com uma abrangência maior sobre os problemas do Estado, a organização da sociedade brasileira; de forma que seus programas e estatutos viabilizem ações de cunho nacional.

\section{3 "Verticalização" das coligações}

A administração e organização do Estado não podem ser pensadas de forma quebrada, como se cada um dos entes federados agissem sobre sociedades diferentes. Os problemas sociais existem em conjunto, sem as divisões técnicas-políticas de organização estatal criadas pelo homem. Assim, para melhor atendimento das necessidades do Estado, os três níveis de governo - o federal, o estadual e o municipal, precisam de ações relativamente compatíveis para persecução de determinados fins, de modo que, sendo importantes os partidos políticos na manifestação do governo, suas alianças eleitorais também precisam ser relativamente compatíveis.

A Resolução $n^{\circ}$. 20.993/2002 expedida pelo TSE (Tribunal Superior Eleitoral), na qual o parágrafo 1 을 do artigo 4 ㅇ incorporou o conteúdo da resposta dada à Consulta $\mathrm{n}^{\circ} .715$, de 26.02.2002; interpretou o artigo 6o da Lei $n^{\circ}$. 9.504/97, no caso particular dos partidos ou coligações que lançam candidatos à eleição para Presidente da República; uma eleição majoritária; dizendo que a diversidade na formação de coligações para eleições proporcionais, só pode existir entre os partidos que componham a mesma coligação nas eleições majoritárias; isso, considerando-se uma mesma circunscrição.

Se a lei permite que os partidos coligados em eleição majoritária formem coligações diferentes entre eles, para eleição proporcional; e somente nesse caso; então, não se poderia falar em inovação no direito quando se diz que os partidos não podem formar coligações para eleições proporcionais com outros partidos, adversários da coligação na eleição majoritária; e por mais óbvio ainda, com partidos em alianças concorrentes à primeira coligação! 
Quando o TSE expediu a Resolução 20.993/02 com o conteúdo do parágrafo 10 do artigo 4우 fez, portanto, norma secundária, interpretativa do direito já positivado na Lei $n^{\circ}$. 9.504/97.

Essa disposição de limitar a formação das coligações de acordo com as coligações feitas em nível nacional; foi chamada de "verticalização das coligações".

"Verticalização de coligações" é expressão usada para se referir às alianças que os partidos fazem para as campanhas eleitorais, e tem o significado de exigir que as deliberações dos partidos sejam verticais, de "cima para baixo".

O magistério do Professor Thales Cerqueira, explica que a verticalização das coligações apresenta diversas vantagens, tais como provocar a fidelidade partidária, gerar a coerência ideológica partidária, ou seja, uma aliança real e não jogo de cena; provocar o fim do coronelismo estadual e a ética no pleito, inviabiliza as alianças articuladas por interesses particulares em desrespeito ao eleitor, evita as alianças com o fim de aumentar tempo de televisão e de rádio; entre outros ${ }^{4}$.

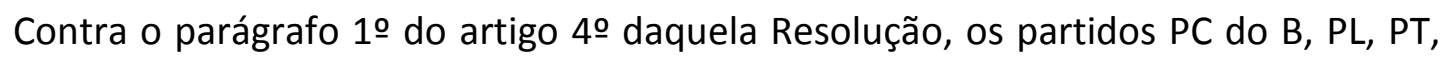
PSB e PPS, ajuizaram a Ação Direta de Inconstitucionalidade no. 2.626-7 - DF. Entretanto, não obtiveram êxito pela impossibilidade do controle abstrato de inconstitucionalidade de ato normativo secundário. Assim, o Congresso Nacional recorreu à Proposta de Emenda à Constituição de $n^{\circ}$. 548, de 11 de junho de 2002, de autoria do ex-senador Bernardo Cabral (PFL/AM); aprovada e transformada na Emenda Constitucional $n^{\circ} .52 / 2006$.

\section{Emenda Constitucional 52/2006 e o fim da verticalização}

A EC $n^{\circ}$. 52/06 deu nova redação ao dispositivo constitucional que trata da autonomia dos partidos; prevalecendo, assim, a total autonomia quanto às coligações partidárias, em prejuízo ao caráter nacional:

Art. 17. [...]

$[\ldots]$

Aula do Professor Thales Tácito Pontes Luz de Pádua Cerqueira no Curso Nacional de Direito Eleitoral, ministrado entre os dias 10 de abril e 13 de maio de 2006, e transmitido pelo Curso Satelitário IELF-LFG. Thales Tácito Pontes Luz de Pádua Cerqueira é Promotor de Justiça / Promotor Eleitoral no Estado de Minas Gerais. 
§ 1 É assegurada aos partidos políticos autonomia para definir sua estrutura interna, organização e funcionamento e para adotar os critérios de escolha e o regime de suas coligações eleitorais, sem obrigatoriedade de vinculação entre as candidaturas em âmbito nacional, estadual, distrital ou municipal, devendo seus estatutos estabelecer normas de disciplina e fidelidade partidária.

[...](Emenda Constitucional no. 52; 2006).

Em face dessa emenda ao texto constitucional, o Conselho Federal da Ordem dos Advogados do Brasil promoveu a Ação Direta de Inconstitucionalidade $n^{\circ}$. 3685, contra o seu

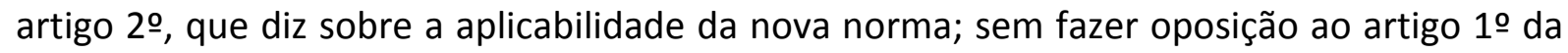
emenda; o qual vem extinguir a obrigatoriedade de verticalização em caso de se formarem coligações.

O Supremo Tribunal Federal admitiu a inconstitucionalidade da parte referente à data de aplicação das novas regras. Devido ao princípio da anterioridade eleitoral, prescrito no artigo 16 da CF/88; o fim da verticalização das coligações político-partidárias não pode ser aplicado nas eleições presidenciais de 2006. A principal parte da EC $n^{\circ} .52 / 06$, que altera a disciplina das coligações partidárias; não foi analisada nessa ADI (ação direta de inconstitucionalidade).

A Associação Nacional do Ministério Público - CONAMP, também havia ajuizado a Ação Direta de Inconstitucionalidade contra a mesma Emenda Constitucional, em desfavor não só de seu artigo $2 \stackrel{0}{ }$, como também do artigo 10; atacando assim a questão do fim da verticalização das coligações. No entanto, a ADI $n^{\circ}$. 3686 da CONAMP foi extinta sob o argumento de que o Ministério Público não pode invadir questão partidária.

Dessa forma, a parte relativa à verticalização das coligações político-partidárias, ligada à interpretação do preceito constitucional do caráter nacional dos partidos políticos, permanece sem análise pelo STF. O Congresso Nacional acabou por revogar a Resolução 20.993/02 do TSE, em seu artigo 4, parágrafo 1ㅇ; e o artigo 6으, parágrafo 1 o da Lei 9.504/97.

A decisão do STF na ADI $n^{\circ}$. 3685 manteve a verticalização de coligações apenas para as eleições de 2006. Em 2010, de acordo com a alteração introduzida no parágrafo 1 o do art. 17 da CF, os partidos poderão realizar as mais diversas alianças políticas com fins eleitorais, tais como, partido A se coligar com partido B na disputa presidencial, e B se coligar com C, em confronto com A, na disputa pelos governos dos Estados; em desrespeito ao caráter nacional dos partidos. Assim, verifica-se que as ideologias partidárias ficaram em planos remotos na ordem do que se espera de um sistema representativo em que se usa não 180

ReVista de Direito PúBlico, LondRINA, V. 2, N. 1, P. 175-184, JAN./ABR. 2007. 
só a votação majoritária, mas também a votação proporcional, a qual visa fortalecer os partidos.

É preciso observar que o Projeto de Lei $n^{\circ}$. 2.679/03 pretende restringir as coligações eleitorais às eleições para Presidente da República, criando em substituição às outras, a federação de partidos, medida esta que tem por finalidade conter o problema da fragmentação partidária.

Esse projeto de lei, também conhecido como a medida que pretende fazer a "Reforma Política" no Brasil, em sua justificativa, explica que um dos problemas mais urgentes a serem resolvidos é a excessiva fragmentação do quadro partidário. Essa fragmentação é responsável pela existência de partidos de ideologias sem nitidez, e até muito semelhantes; o que revela sua pouca efetividade no processo político do país. Tais partidos precisam das coligações para conseguirem alcançar o quociente eleitoral e, assim, elegerem seus candidatos.

Ainda em sua obra, o Prof. Thales Cerqueira (2005, p. 147) expõe sobre os efeitos da verticalização:

[...] deixa o cenário político bem definido, mostrando quais são os partidos de direita, de esquerda e de centro, além de impedir coligações espúrias e sem ideologias similares no território nacional, o que não é aceito por partidos políticos que justificam as diferenças geográficas do território nacional, que provocam um natural disparate ideológico, vertente de uma democracia tipicamente brasileira. Vislumbra-se no projeto de lei comentado, que a união desses partidos em federações, de caráter mais duradouro que as coligações para eleições, possibilitará diminuir o casuísmo das alianças, e viabilizará a atuação conjunta dos mesmos nas casas legislativas.

Conforme preleciona o Prof. Thales Cerqueira (2005, p. 126) em relação ao Projeto de Lei $n^{\circ}$. 2.679/03:

As coligações partidárias somente poderão ser feitas nas eleições à Presidência da República e Senado Federal, ou seja, somente nestas eleições majoritárias, jamais em outras majoritárias ou proporcionais.

Assim, verifica-se o Congresso Nacional tem a intenção de diminuir, ou quase extinguir o uso de coligações. Nessa medida, a Emenda Constitucional $n^{\circ}$. 52/02 direcionouse contrariamente a solução de um dos problemas levantados nas discussões já realizadas 
no Congresso Nacional; qual seja, do uso das coligações partidárias para permitir que a proliferação de partidos não seja barrada, na prática, por não alcançarem eles o quociente eleitoral.

O confronto entre o artigo 10 da EC $n^{\circ} .52 / 06$, e a proposta de acabar com as coligações partidárias nas eleições; mostra que a modificação constitucional é mais um produto do casuísmo comum na produção normativa deste país, que necessidade de desenvolvimento de nosso processo eleitoral.

\section{Conclusão}

Se os partidos políticos devem apresentar, cada um, seu programa de organização social, de forma nítida e aplicável, não é possível a formação das mais diversas coligações partidárias, ao longo do território nacional; se elas podem até mesmo, mostrarem-se contraditórias. Isso evidenciaria que, na verdade, uma das propostas apresentadas não corresponde às reais ideologias partidárias; ora unidas apenas com fins eleitorais. Desse modo, o utilitarismo das coligações entre partidos com ideologias até mesmo contrárias, caracteriza sim, o desrespeito ao eleitorado nacional.

Além disso, se o próprio Congresso Nacional, que vem discutindo a Reforma Política desde 1995, entendeu ser problemático o uso de coligações partidárias como vem sendo feito desde 1988; como pode o Congresso, modificar o texto constitucional diante de uma interpretação feita pelo Tribunal Superior Eleitoral, na qual os interesses dos diversos partidos políticos foram chamados a atender a moralidade nos pleitos eleitorais?

Faz-se mister que o caráter nacional dos partidos políticos volte a ser compreendido em seu significado constitucional anterior ao casuísmo da emenda comentada. Os partidos, como já identificado pelo Congresso Nacional, utilizam-se constantemente das coligações, na medida e no modo em que elas forem convenientes ao alcance do poder em cada eleição e em cada região do país. Infelizmente, não foi discutido ainda o perigo da liberação total para formação dessas alianças. Num país onde se pretende a fortificação de partidos políticos, e em que é baixíssima a fidelidade partidária; anda ao contrário as decisões que privilegiam a autonomia absoluta dos partidos nos momentos em que lutam para conquistar o poder. 


\section{Referências}

BRASIL, Constituição (1988). Constituição da República Federativa do Brasil. Brasília, DF, 1988.

BRASIL, Lei $n^{\circ}$. 9.096, de 19 de setembro de 1995. Dispõe sobre partidos políticos, regulamenta os arts. 17 e 14, § 3으, inciso V, da Constituição Federal. Diário Oficial da União, Brasília, DF, publicado dia 20.09.1995.

BRASIL, Câmara dos Deputados. Projetos de Leis e Outras Proposições. Projeto de Lei $n^{\circ}$. 2679, de 03 de dezembro de 2003. Disponível em:

<http://www2.camara.gov.br/proposicoes/loadFrame.html?link=http://www.camara.gov.br /internet/sileg/prop_lista.asp?fMode=1\&btnPesquisar=OK\&Ano=2003\&Numero=2679\&sigla $=\mathrm{PL}>$.

BRASIL, Câmara dos Deputados. Projeto de Emenda à Constituição $n^{\circ}$. 548, de 11 de junho de 2002. Disponível em:

<http://www2.camara.gov.br/proposicoes/loadFrame.html?link=http://www.camara.gov.br /internet/sileg/prop_lista.asp?fMode=1\&btnPesquisar=OK\&Ano=2002\&Numero=548\&sigla= PEC>.

BRASIL, Emenda Constitucional n ${ }^{\circ}$ 52, de 08 de março de 2006. Dá nova redação ao $\S 10$ do art. 17 da Constituição Federal para disciplinar as coligações eleitorais. Diário Oficial da União, Brasília, DF, publicada dia 09.03.2006.

CERQUEIRA, Thales Tácito Pontes Luz de Pádua. Sinopse TTC de Direito Eleitoral para concursos públicos. 4. ed. São Paulo : TTC, 2005.

MACIEL, Eliane Cruxên Barros de Almeida. Reforma Política e construção democrática. Revista de Informação Legislativa, Brasília, v. 41, n. 161, p. 9-14, jan./mar. 2004.

SANTOS, Eurico a. Gonzalez Cursino. Comentários ao PL 2.679/2003, da Comissão de Reforma Política da Câmara dos Deputados. Revista de Informação Legislativa, Brasília, v. 41, n. 161, p. 15-21, jan./mar. 2004. 
